\title{
Challenges in Understanding the Risks to Natural and Semi-Natural Vegetation from Ozone Exposure
}

\author{
J. Neil Cape ${ }^{1 *}$, Serain Bassin², Jürg Fuhrer ${ }^{2}$, Giacomo Gerosa ${ }^{3}$, Rocio Alonso ${ }^{4}$, \\ Benjamin Gimeno ${ }^{4}$, Ludger Grünhage ${ }^{5}$, Teis N. Mikkelsen ${ }^{6}$, Gina Mills ${ }^{7}$ \\ ${ }^{1}$ Centre for Ecology \& Hydrology \\ Bush Estate, Penicuik, Midlothain EH26 0QB, United Kingdom \\ ${ }^{2}$ Federal Department of Economic Affairs DEA, Agroscope Reckenholz-Tänikon Research Station ART \\ Air Pollution and Climate Group \\ Reckenholzstrasse 191, 8046 Zurich, Switzerland \\ ${ }^{3}$ Research Centre for Air Pollution and Ecosystems, Università Cattolica del Sacro Cuore \\ Via Musei 41, 25121 Brescia, Italy \\ ${ }^{4}$ Ecotoxicology of Air Pollution, CIEMAT \\ Avda. Complutense 22 (ed. 70), 28040 Madrid, Spain \\ ${ }^{5}$ Department of Plant Ecology, University of Giessen \\ Heinrich-Buff-Ring 26-32, 35392 Giessen, Germany \\ ${ }^{6}$ Ris $\varnothing$ National Laboratory, Biosystems Department, Technical University of Denmark \\ Frederiksborgvej 399, 4000 Roskilde, Denmark \\ ${ }^{7}$ Centre for Ecology \& Hydrology, Environment Centre Wales \\ Deiniol Road, Bangor, Gwynedd, LL57 2UW, United Kingdom
}

Received: 5 December 2007. Accepted 10 December 2007.

\begin{abstract}
Summary
The effects of tropospheric ozone on crops and forests have been studied intensively, but effects on natural and semi-natural plant communities are poorly understood. This lack of understanding arises partly from a lack of experimental studies of whole mature communities, and the effects of ozone on competition and interactions with climate, nutrition etc., and partly from a lack of knowledge of the factors which predispose individual plant species to ozone damage. A recent review of the effects of ozone on grasslands (Bassin et al., 2007a) has drawn attention to the problems involved; this paper seeks to identify the practical issues that must be addressed in improving our knowledge and thereby identifying the risks associated with ozone exposure. This is a necessary first step before mitigation strategies can be developed.
\end{abstract}

Key-words: plant communities, field fumigation, ecological response, tropospheric ozone.

\section{Introduction}

This paper summarises the discussions and conclusions of a working group which was established to examine the future role of experimental approaches to assessing the risk from ozone to natural and semi-natural vegetation in Europe.

Ozone is a phytotoxic gas formed in sunlight from the reactions of nitrogen oxides and volatile organic compounds. Harmful effects on vegetation are generally only observed when ozone concentrations exceed 40 parts per billion $\left(\mathrm{ppb}=\mathrm{nl} \mathrm{l}^{-1}\right)$, and several metrics have been introduced to relate ozone concentrations (exposure) to observed effects, in terms of visible injury or growth/yield reduction, e.g. (Legge et al., 1995). In Europe, the current metric is the AOT40, or accumulated exposure of ozone above a threshold of $40 \mathrm{ppb}$ during the growing season (Fuhrer et al., 1997), although there have been moves recently to use a more direct metric of the accumulated stomatal flux into plants above a threshold rate that is related to the plant's ability to detoxify the absorbed ozone (AFSt) (Karlsson et al., 2004).

\footnotetext{
* Corresponding Author: Tel.: +44 131 4458533; Fax: +44 131 4453943. E-mail: jnc@ceh.ac.uk
} 
Ozone concentrations at the earth's surface are rising across the northern hemisphere in response to increasing global emissions of nitrogen oxides and volatile organic hydrocarbons. It is predicted that by 2050 many regions of Europe will experience annual average concentrations that exceed the currently used threshold for effects on plants of 40 parts per billion $\left(\mathrm{nl} \mathrm{l}^{-1}\right)$ (Langner et al., 2005). Even if future predictions of ozone over the different regions of Europe are somewhat uncertain, there is already evidence that ozone is having effects now on natural and semi-natural vegetation (Hayes et al., 2007b).

Experimental research on the effects of ozone on vegetation has concentrated on the effects on agricultural crops and on forests, presumably because of the direct links to economic losses. In the case of forests, there has been an additional interest in overall forest health, linked to amenity aspects of forest, rather than simply to timber production. However, for natural and semi-natural vegetation the economic incentive is less obvious. The motivational factors important to this type of ecosystem are the threat to biodiversity of natural habitats, and the long-term impacts that may ensue in terms of ecosystem function and services.

We review here the current status of research on the effects of ozone on non-crop and non-forest vegetation in Europe, recognising that many semi-natural ecosystems are used in agriculture, albeit with low intensity of intervention such as fertilizer application, active management, or grazing. The distinction is perhaps that natural and semi-natural ecosystems are characterised by complex communities of species, often long-established, and adapted to the particular microclimatic properties and nutrient availability at the site.

\section{Assessment of risk}

Attempts to protect European semi-natural vegetation from the adverse impacts of ozone, in the context of the UNECE Convention on Long-Range Transboundary Air Pollution (UNECE, 2007), rely on knowledge of the sensitivity to ozone of different vegetation types (Mills et al., 2007). Risk assessment maps could, in principle, be established by spatially explicit assessment of potential impacts of ozone on the floristic composition and productivity of plant communities, and identification of communities at risk. Unfortunately, the required scientific basis is still insufficient, due to a lack of:

a) Studies which allow us to link ozone effects with ozone fluxes, and consequently the dose taken up by the plants;

b) Investigations of ozone effects on plants growing under realistic climatic and edaphic conditions;

c) Investigations of ozone effects on intact communities and ecosystem processes;

d) Studies which assess the ozone sensitivity of different vegetation types and the underlying causes for differences in sensitivity.

Each of these deficiencies is addressed in detail below.

\subsection{Exposure metrics}

Metrics for evaluating the sensitivity of seminatural vegetation to ozone (Critical levels) are still based on measures of exposure (e.g. AOT40), but there has been a move towards more mechanistic measures of ozone uptake ('critical dose'), as already established for a few crop and tree species (Grünhage et al., 2004; Karlsson et al., 2004; Massman, 2004; Matyssek et al., 2004; Emberson et al., 2007; Harmens et al., 2007a; Pleijel et al., 2007; Gerosa et al., 2008). Estimating ozone uptake requires basic knowledge and understanding of the physiology of the species of interest, as well as knowledge of ozone exposure. Such knowledge is only available for wheat, potato, and beech at present. The complexity of the semi-natural communities and the number of component species has hampered the derivation of dose-response relationships. Although ozone deposition fluxes have been measured over different vegetation types, it has not been possible to link the fluxes with effects, mainly due to the lack of fumigation experiments on intact communities. The ultimate requirement is the derivation of an appropriate flux-based metric (Critical dose) for natural and semi-natural ecosystems by linking measured and modelled uptake fluxes with observed effects.

\subsection{Challenges posed by natural systems}

The major difference between natural and managed ecosystems is that the former are characterized by communities of different species, 
whereas the latter comprise only a few species, and in the case of agricultural crops, often only one genotype of a single species. Consequently, approaches to studying the effects of ozone on natural and semi-natural systems must differ from those applied to intensively managed systems, and have to take into account not only the direct effects of ozone on particular species, but the interactions among the different species and the consequent evolution of the community as a whole. Future investigations need to consider whether community productivity/composition might be influenced also indirectly through ozone-induced changes in ecosystem characteristics such as water and carbon budgets.

\subsection{Experimental approaches}

The current Critical levels (AOT40) for seminatural vegetation (UNECE, 2007) are predominantly based on experiments using single plants and mesocosms exposed in open-top chambers (OTC). Research conducted in controlled environments such as solardomes or open-top chambers inevitably introduces some constraints on the natural variability of the growing conditions experienced by the test plants. Extrapolation beyond the climatic and edaphic conditions created in experimental systems can be misleading, since interactions with climate and the other abiotic and biotic stresses experienced by plant communities in the field are avoided, and intra-specific competition may be ignored (Bassin et al., 2007a). Therefore, the climatic and edaphic conditions in any experimental approaches to assessing ozone effects need to be representative for the original habitat of the investigated communities in terms of climate, resource availability, plant age, and competition. So far it has not been possible to assess differences in ozone sensitivity between various vegetation types due to a lack of comparable fumigation experiments. For the same reason, it has not been possible to identify community characteristics which potentially are related to ozone sensitivity (e.g. productivity, functional composition, species number).

\section{Status of current knowledge}

Most of the available information and research results for natural and semi-natural vegetation come from studies on grasslands, which as a broad description include a variety of habitats described as meadows and fens, as well as agricultural grassland used for grazing, albeit maintained to conserve species diversity. The problems associated with evaluating the effects of ozone on grasslands, which also apply to other natural and semi-natural ecosystems, have recently been identified and critically reviewed (Bassin et al., 2007a). Some important conclusions from this review are worth emphasising here:

- Although three traits of individual plant species were identified that are linked to ozone sensitivity through their links to relative growth rate (stomatal control, specific leaf area, biochemical defence capacity), the role of these traits in determining the response to ozone of individual plant species growing in a community does not provide any predictive capacity regarding competitive advantage or long-term fate of that species. Undoubtedly, we are still in the early stages of recognising the relative sensitivity to ozone of different individual plant species, even though some progress has been made in bringing the available data together (Mills et al., 2007) and in establishing some of the properties that might be useful in predicting responses to ozone (Jones et al., 2007).

- The sensitivity of plant communities to ozone cannot readily be predicted from knowledge of the behaviour of their component species, because inter-species interactions, both positive and negative, appear to depend on factors such as nutrient availability (Bassin et al., 2007b) and microclimatic conditions, which vary greatly from place to place. There does not appear to be a very strong link between species functional type composition and overall ozone sensitivity (Hayes et al., 2007a).

- There are some indications that the sensitivity to ozone of communities is positively related to productivity, and therefore, that species grown under favourable growth conditions or in productive habitats (e.g. agricultural improved grassland) are most sensitive.

- The time factor for community responses may be very much longer than for individ- 
ual species, because of changes in species composition, and also changes in genetic composition within individual species, which may only appear after several generations. Any consequent loss of genetic diversity, and possible greater sensitivity to other biotic and abiotic stresses, might take many years to become apparent. Such long-term effects are very difficult (and expensive) to study in long-term controlled exposure experiments, and even in open-field experiments where communities are exposed to occasional or infrequent acute stress.

- There are very few data on the effects of ozone on mature communities, as opposed to reconstructed or sown communities that have been created for experimental assessments. Four such studies were identified in the review (Evans and Ashmore, 1992; Barbo et al., 1998; Thwaites et al., 2006; Volk et al., 2006), and even there, only one study (pre-alpine grassland) has lasted longer than 3 years. This lack of long-term data leads to real problems in extrapolating over long time scales, or extending the results from a few experiments to other types of community.

- Most experimental procedures rely on controlling at least some of the growing conditions (such as avoiding grazing, control of water supply) or changing exposure conditions from those that are experienced in the field (e.g. regular exposure to elevated ozone concentrations, or constant wind turbulence in chambers). Recreating or transplanting microcosms is an important and necessary positive step in moving away from studies on individual plant species, but even for such experimental subjects, the difference in environmental growing conditions may lead to great uncertainty in extrapolating to the field.

\section{The way forward: approaches and issues}

There is a vast range of habitats and ecosystems which could be studied. Controlled exposures of individual natural plant species to ozone have shown a wide range of responses, with both growth stimulation and growth inhibition, neither of which is necessarily correlated with the expression of visible injury (Bassin et al., 2007 a). Both types of response may prove deleterious to semi-natural systems, in that the pattern of competition in communities is altered, with growth stimulation leading to the possibility of greater competitive success at the expense of species where growth is inhibited. However, it also appears that direct effects of ozone on growth are intimately linked to other stress factors, such as drought and low temperatures, and to the availability of nutrients (Sanz et al., 2007). Although management of semi-natural systems is usually non-intensive, grazing patterns are likely to have a profound effect at the ecosystem level, and therefore will influence any direct and indirect effects of ozone. Moreover, the effects of ozone on grasslands may in turn alter grazing patterns because of a change in the nutritional value of the pasture (Sanz et al., 2005; Bender et al., 2006). Consequently, direct experimental approaches to the understanding of ozone effects on semi-natural ecosystems will either need to control such interactions (e.g. by excluding grazing pressure, or by mowing) or by specifically including them in any experimental design (e.g. controlled addition of nitrogen).

\subsection{Ozone fluxes: stomatal conductance and ozone uptake}

In order to relate the results of experimental studies on natural/semi-natural vegetation to the outcomes of studies on forests and agricultural crops, and to work within the framework for Critical Levels in terms of ozone fluxes, future research should include the measurement of ozone fluxes at the canopy (community) level. The plant size and structure of semi-natural vegetation allows measurements of deposition fluxes and ozone effects to be made in fumigation facilities on communities which are replicated in terms of species composition, age, growth rates, and edaphic conditions, and consequently in canopy conductance, the key parameter for the estimation of ozone uptake. This is of major importance, since linking the experimentally induced ozone effects with deposition fluxes measured at other sites is only valid when it is possible to provide evidence that stomatal ozone uptake (or at least canopy conductance) is similar between two sites. Therefore, canopy conductance measurements will need to be carried out using closed/dynamic chambers $\left(\mathrm{CO}_{2} /\right.$ 
water vapour), in combination with infraredmeasurements of canopy temperature. These measurements provide the basis for accurate modelling of stomatal ozone uptake and the establishment of dose-response functions at canopy level. Where plot sizes are small, for example in exposure chambers or free-air fumigation facilities, the use of micro-meteorological approaches (e.g. eddy covariance) is not possible. However, such measurements could (and should) be used in open field situations to measure ozone fluxes, with sufficient ancillary measurements $\left(\mathrm{CO}_{2}, \mathrm{H}_{2} \mathrm{O}\right.$, heat fluxes) to permit the separation of stomatal and non-stomatal ozone uptake by the canopy.

Issues to be addressed:

- Measurement techniques for canopy conductance $\left(\mathrm{CO}_{2}, \mathrm{H}_{2} \mathrm{O}\right)$.

- Coordination and inter-calibration of gradient and eddy-flux measuring techniques $\left(\mathrm{O}_{3}\right.$, $\mathrm{CO}_{2}, \mathrm{H}_{2} \mathrm{O}$ ), and canopy conductance measurement techniques.

- Choice of modelling approach for ozone uptake.

- Required model input parameters.

\subsection{Ozone fluxes: Effective ozone dose}

By using in-canopy measurement of ozone concentrations and leaf porometry on selected species, it will be possible to estimate the ozone dose taken up by different species (species-specific dose-effect relationships) growing in different communities. This in itself may give useful information for modelling the responses of other species in other conditions, for example, by ascertaining whether ozone fluxes to a particular species depend on the community in which it is growing. However, generalisation of such responses may not be straightforward; recent results have shown that ozone sensitivity does not appear to be closely related to stomatal conductance, and no clear differences in gas exchange rates could be attributed to Leguminosae and Poaceae families growing in the field, with intra-genus variation being more important than differences found between families (Alonso et al., 2007).

At the community level, repeated vegetation analyses should reveal whether species-specific differences in ozone uptake and sensitivity lead to changes in species composition and species diversity. A variety of community characteristics would need to be investigated in terms of their relationship to potential ozone impact, such as productivity, functional composition, phenology, senescence, transpiration rates, etc. Corresponding quantitative parameters such as dry matter production, development of leaf area index (LAI), development of Normalized Difference Vegetation Index (NDVI) (Bassin et al., 2007b), canopy transpiration etc. could then be related to the estimated ozone dose taken up by the community.

\subsection{Ozone tolerance of individual species}

Although many studies have been made of the ozone sensitivity of individual plants, assessment of species growing in their natural environment under intra- and inter-specific competition is now required, in order to improve our understanding of species-specific strategies of ozone stress avoidance and tolerance, and to evaluate the inter-specific similarity of the reactions to ozone stress. The measurements to assess response need to consider both physiological and morphological analyses.

Issues to be addressed:

- Visible leaf injury assessment (starting time, characterisation and development).

- Physiological measurements, such as stable isotope analysis for ${ }^{13} \mathrm{C} /{ }^{18} \mathrm{O}$, soluble/insoluble carbohydrates, content of leaf pigments (including chlorophylls), quantification of secondary defence substances, photosynthetic activity/stomatal conductance, etc. (Scebba et al., 2006).

- Morphological and cytochemical investigations, such as cell wall reactions, chloroplast morphology, starch accumulation patterns, HR-like (hypersensitive reaction-like) markers, oxidation of cell content, light-exposure dependency, signals of accelerated cell senescence.

\subsection{Ozone tolerance of communities}

The comparison of ozone sensitivity across different vegetation types is a prerequisite for the establishment of ozone risk assessment maps for Europe. It enables the validation of the different prediction approaches based on the European Database for species from semi-natural vegetation (Harmens et al., 2007b; Jones et al., 2007; Mills, et al., 2007). It would also help to 
identify community characteristics which are relevant for ozone sensitivity/tolerance, such as productivity (dependent on nutrient availability, climate, edaphic conditions), age, functional composition and species-richness of the community. The main issue to be addressed is the selection of a sufficiently wide range of communities and habitats that the interactions with potential modifying factors can be quantified and generalised.

\section{Conclusions}

Open-air field fumigation systems, such as that pioneered for semi-natural vegetation in Switzerland (Volk et al., 2003), appear to be necessary - but the cost of such systems, and the likely need for long-term treatments, means that they need to be used in addressing specific hypotheses that have been derived from more restricted and controlled experiments in chambers. However, the limitations of continued experimentation in controlled chambers must be recognised if progress in understanding is to be made. Such experiments must be used to address some of the basic lack of understanding of the many factors that interact with ozone stress, so that the knowledge gained can be used to complement and help interpret the results obtained from open-air exposure experiments. Without such understanding, our ability to extrapolate the field results to different communities and different ecosystems will be greatly curtailed. This is particularly important given that we expect community responses to ozone to occur over time-scales that will overlap with changes in atmospheric $\mathrm{CO}_{2}$ concentrations and in regional climate patterns (Langner et al., 2005), as well as changes to regional patterns of atmospheric nitrogen deposition arising from changes in legislation and fuel use.

Although a small number of open-air field experiments on the effects of ozone on natural or semi-natural vegetation are planned, or have started recently in Europe, there is a clear need for greater investment if we are to be able to forecast the likely long-term consequences of increasing (or even current) ozone concentrations on the sustainability of unmanaged (natural) or low management (semi-natural) ecosys- tems which represent the range of biodiversity across Europe - not just for plant life, but also for the above and below ground fauna which depend on the existence of such habitats. Apart from potential effects on biodiversity and conservation, the soils of natural and semi-natural ecosystems in Europe (e.g. grasslands) act as a significant carbon sink and storage pool, but effects of ozone (e.g. accelerated senescence) on C storage are not known (Felzer et al., 2005).

The scientific challenge is to relate effects of ozone on the whole system to the canopy flux - the complexity of species-rich ecosystems is different from the single species approach used for crops and forest trees. The likelihood that communities will adapt to ozone stress in different ways from single species, and in ways which cannot be predicted at present, means that experimental data are required if the risks to future sustainability in the face of rising background ozone concentrations are to be managed.

\section{References}

Alonso R., Bermejo V., Sanz J., Valls B., Elvira S., Gimeno B.S. 2007. Stomatal conductance of semi-natural Mediterranean grasslands: Implications for the development of ozone critical levels. Environmental Pollution, 146:692-698.

Barbo D.N., Chappelka A.H., Somers G.L., Miller-Goodman M.S., Stolte K. 1998. Diversity of an early successional plant community as influenced by ozone. New Phytologist, 138:653-662.

Bassin S., Volk M., Fuhrer J. 2007a. Factors affecting the ozone sensitivity of temperate European grasslands: An overview. Environmental Pollution, 146:678-691.

Bassin S., Volk M., Suter M., Buchmann N., Fuhrer J. 2007b. Nitrogen deposition but not ozone affects productivity and community composition of subalpine grassland after $3 \mathrm{yr}$ of treatment. New Phytologist, 175:523-534.

Bender J., Muntifering R.B., Lin J.C., Weigel H.J. 2006. Growth and nutritive quality of Poa pratensis as influenced by ozone and competition. Environmental Pollution, 142:109-115.

Emberson L.D., Buker P., Ashmore M.R. 2007. Assessing the risk caused by ground level ozone to European forest trees: A case study in pine, beech and oak across different climate regions. Environmental Pollution, 147:454-466.

Evans P.A., Ashmore M.R. 1992. The Effects of Ambient Air on a Seminatural Grassland Community. Agriculture Ecosystems \& Environment, 38:91-97. 
Felzer B., Reilly J., Melillo J., Kicklighter D., Sarofim M., Wang C., Prinn R., Zhuang Q. 2005. Future effects of ozone on carbon sequestration and climate change policy using a global biogeochemical model. Climatic Change, 73:345-373.

Fuhrer J., Skarby L., Ashmore M.R. 1997. Critical levels for ozone effects on vegetation in Europe. Environmental Pollution, 97:91-106.

Gerosa G., Marzuoli R., Desotgiu R., Bussotti F., Ballarin-Denti A. 2008. Visible leaf injury in young trees of Fagus sylvatica L. and Quercus robur L. in relation to ozone uptake and ozone exposure. An OpenTop Chambers experiment in South Alpine environmental conditions. Environmental Pollution, in Press.

Grünhage L., Krupa S.V., Legge A.H., Jäger H. 2004. Ambient flux-based critical values of ozone for protecting vegetation: differing spatial scales and uncertainties in risk assessment. Atmospheric Environment, 38:2433-2437.

Harmens H., Mills G., Emberson L.D., Ashmore M.R. 2007a. Implications of climate change for the stomatal flux of ozone: A case study for winter wheat. Environmental Pollution, 146:763-770.

Harmens H., Mills G., Hayes F., Jones L., Norris D., Fuhrer J., 2007b. Air pollution and vegetation: ICP Vegetation Annual Report 2006/2007. CEH, Bangor, 37.

Hayes F., Jones M.L.M., Mills G., Ashmore M. 2007a. Meta-analysis of the relative sensitivity of semi-natural vegetation species to ozone. Environmental Pollution, 146:754-762.

Hayes F., Mills G., Harmens H., Norris D. 2007b. Evidence of widespread ozone damage to vegetation in Europe (1990-2006). http://icpvegetation.ceh.ac.uk/publications.htm.

Jones M.L.M., Hayes F., Mills G., Sparks T.H., Fuhrer J. 2007. Predicting community sensitivity to ozone, using Ellenberg Indicator values. Environmental Pollution, 146:744-753.

Karlsson G.P., Karlsson P.E., Soja G., Vandermeiren K., Pleijel H. 2004. Test of the short-term critical levels for acute ozone injury on plants - improvements by ozone uptake modelling and the use of an effect threshold. Atmospheric Environment, 38:2237-2245.

Langner J., Bergstrom R., Foltescu V. 2005. Impact of climate change on surface ozone and deposition of sulphur and nitrogen in Europe. Atmospheric Environment, 39:1129-1141.

Legge A.H., Grünhage L., Nosal M., Jäger H.J., Krupa S.V. 1995. Ambient ozone and adverse crop response: An evaluation of North American and European data as they relate to exposure indices and critical levels. Journal of Applied Botany-Angewandte Botanik, 69:192-205.
Massman W.J. 2004. Toward an ozone standard to protect vegetation based on effective dose: a review of deposition resistances and a possible metric. Atmospheric Environment, 38:2323-2337.

Matyssek R., Wieser G., Nunn A.J., Kozovits A.R., Reiter I.M., Heerdt C., Winkler J.B., Baumgarten M., Haberle K.-H., Grams T.E.E. 2004. Comparison between AOT40 and ozone uptake in forest trees of different species, age and site conditions. Atmospheric Environment, 38:2271-2281.

Mills G., Hayes F., Jones M.L.M., Cinderby S. 2007. Identifying ozone-sensitive communities of (semi-)natural vegetation suitable for mapping exceedance of critical levels. Environmental Pollution, 146:736-743.

Pleijel H., Danielsson H., Emberson L., Ashmore M.R., Mills G. 2007. Ozone risk assessment for agricultural crops in Europe: Further development of stomatal flux and flux-response relationships for European wheat and potato. Atmospheric Environment, 41:3022-3040.

Sanz J., Bermejo V., Gimeno B.S., Elvira S., Alonso R. 2007. Ozone sensitivity of the Mediterranean terophyte Trifolium striatum is modulated by soil nitrogen content. Atmospheric Environment, 41:89528962.

Sanz J., Muntifering R.B., Bermejo V., Gimeno B.S., Elvira S. 2005. Ozone and increased nitrogen supply effects on the yield and nutritive quality of Trifolium subterraneum. Atmospheric Environment, 39:58995907.

Scebba F., Giuntini D., Castagna A., Soldatini G., Ranieri A. 2006. Analysing the impact of ozone on biochemical and physiological variables in plant species belonging to natural ecosystems. Environmental and Experimental Botany, 57:89-97.

Thwaites R.H., Ashmore M.R., Morton A.J., Pakeman R.J. 2006. The effects of tropospheric ozone on the species dynamics of calcareous grassland. Environmental Pollution, 144:500-509.

UNECE 2007. Mapping critical levels for vegetation. Manual on methodologies and criteria for modelling and mapping critical loads and levels and air pollution effects, risks and trends. UNECE Convention on Long-range Transboundary Air Pollution. http://www. icpmapping.org/.

Volk M., Bungener P., Contat F., Montani M., Fuhrer J. 2006. Grassland yield declined by a quarter in 5 years of free-air ozone fumigation. Global Change Biology, 12:74-83.

Volk M., Geissmann M., Blatter A., Contat F., Fuhrer J. 2003. Design and performance of a free-air exposure system to study long-term effects of ozone on grasslands. Atmospheric Environment, 37:1341-1350. 